\title{
Scale-Up of Cluster Beam Deposition to the Gram Scale with the Matrix Assembly Cluster Source for Heterogeneous Catalysis (Catalytic Ozonation of Nitrophenol in Aqueous Solution)
}

\author{
Rongsheng Cai, Francesca Martelli, Jerome Vernieres, Stefania Albonetti, Nikolaos Dimitratos, \\ Chedly Tizaoui, and Richard E. Palmer*
}

Cite This: ACS Appl. Mater. Interfaces 2020, 12, 24877-24882

Read Online

\section{ACCESS I Lل山ll Metrics \& More | 回 Article Recommendations}

Supporting Information

ABSTRACT: The deposition of precisely controlled clusters from the beam onto suitable supports represents a novel method to prepare advanced cluster-based catalysts. In principle, cluster size, composition, and morphology can be tuned or selected prior to deposition. The newly invented matrix assembly cluster source (MACS) offers one solution to the long-standing problem of low cluster deposition rate. Demonstrations of the cluster activities under realistic reaction conditions are now needed. We deposited elemental silver (Ag) and gold $(\mathrm{Au})$ clusters onto gram-scale powders of commercial titanium dioxide $\left(\mathrm{TiO}_{2}\right)$ to investigate the catalytic oxidation of nitrophenol (a representative pollutant in water) by ozone in aqueous solution, as relevant to the removal of waste drugs from the water supply. A range of

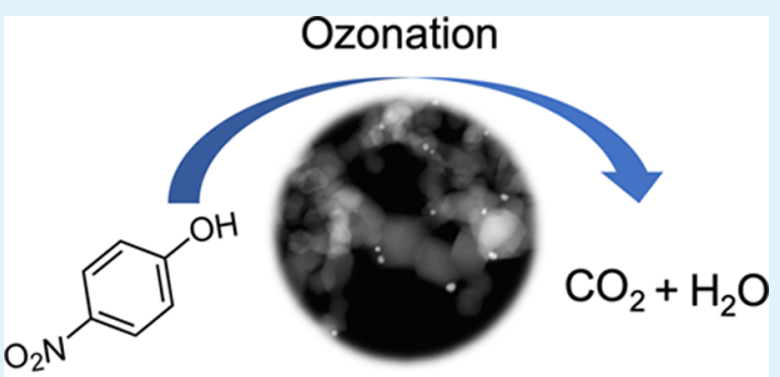

Cluster beam deposition techniques, including scanning transmission electron microscopy (STEM), Brunauer-Emmett-Teller (BET) surface area test, and X-ray photoelectron spectroscopy (XPS), were employed to reveal the catalyst size, morphology, surface area, and oxidation state. Both the $\mathrm{Ag}$ and $\mathrm{Au}$ cluster catalysts proved active for the nitrophenol ozonation. The cluster catalysts showed activities at least comparable to those of catalysts made by traditional chemical methods in the literature, demonstrating the potential applications of the cluster beam deposition method for practical heterogeneous catalysis in solution.

KEYWORDS: heterogeneous catalysis, cluster beam deposition, nitrophenol ozonation, water treatment, metal clusters, scale-up, matrix assembly cluster source (MACS), titanium dioxide powder

\section{INTRODUCTION}

Cluster beam deposition (CBD) is a vacuum-based, solventfree method to synthesize metal clusters on surface. ${ }^{1}$ The clusters produced have no chemical ligands, and contamination levels should be low, so the intrinsic properties of the clusters can be controlled, investigated, and exploited. This may allow the rapid prototyping of novel, cluster-based catalysts for various reactions, since the capacity to vary cluster composition and size compares favorably with the traditional chemical methods. The clusters are simply formed by condensing individual atoms of the material vaporized, ${ }^{2}$ so composited clusters (binary, ternary, and beyond) should be relatively easy to synthesize. Recent studies have shown precise control of cluster morphology, ${ }^{3}$ structure, ${ }^{4}$ and size ${ }^{5}$ by regulating the condensation conditions and combining with a time-of-flight mass filter. ${ }^{6}$ However, the CBD method has been largely limited to surface science studies by the low cluster deposition rate (ng to $\mu \mathrm{g} / \mathrm{h}$ ). Thus, scale-up of the cluster production rate is a crucial step to translate this technique into practical applications. ${ }^{7}$ For this reason, a new type of source, the matrix assembly cluster source (MACS), has been developed in our group with potential for considerable scaleup. ${ }^{8,9}$ The formation of clusters in the MACS has been studied both experimentally ${ }^{8,10}$ and theoretically. ${ }^{11,12}$ It is based on the assembly of atoms, initiated by ion beam impacts, in a metalloaded, cryogenically cooled rare gas (Ar) matrix. The latest study ${ }^{13}$ shows that the cluster deposition rate from the MACS can reach $\sim 10 \mathrm{mg}$ of clusters per hour, which is enough to prepare cluster-based catalysts at the gram-scale for $R \& D$ studies at the test tube level. While the first investigations of clusters from the MACS have been reported, heterogeneous catalysis in solution has yet to be demonstrated.

Here, the oxidation of nitrophenol by ozone in aqueous solution using clusters deposited on commercial powder supports is demonstrated. Nitrophenol, a nitroaromatic

Received: March 31, 2020

Accepted: May 11, 2020

Published: May 11, 2020 

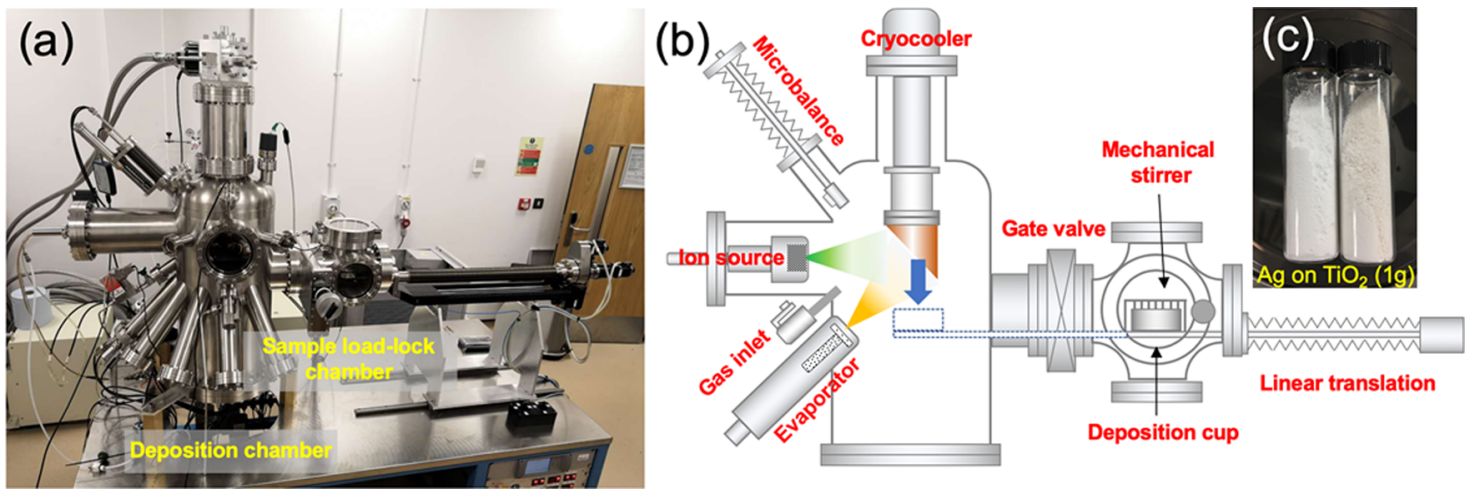

Figure 1. New MACS 3 system for the preparation of cluster catalysts at the gram scale. (a) Photograph and (b) schematic diagram of the system. (c) Photograph of the Ag cluster on $\mathrm{TiO}_{2}$ powder catalyst produced $(1 \mathrm{~g})$, showing the color change from white to brown.

chemical, is a model compound for the water treatment industry, being toxic, mutagenic, and biorefractory in the aquatic environment. It is widely detected as an organic pollutant in industrial and agricultural wastewaters. ${ }^{14,15}$ The maximum allowable contaminant level (for $p$-nitrophenol) in water is only around $10 \mathrm{ng} / \mathrm{L}$, since it can irritate eyes and skin, damage kidneys and the liver, cause methemoglobin, etc. ${ }^{16,17}$ The ozonation of nitrophenol is an important reaction commonly used to remove this toxic substance from environmental media. ${ }^{18}$ Although the use of catalysts (e.g., metals supported on oxide powders) in chemical reactions (e.g., nitrophenol reduction) has been found effective to accelerate reaction rate, ${ }^{19,20}$ catalytic ozonation with nanoclusters has not yet been reported. One of the issues in heterogeneous catalytic ozonation is catalyst agglomeration due to $\mathrm{pH}$ changes in water and catalyst retrieval and reuse, and we address the latter problem here. ${ }^{21,22}$

In this work, we demonstrate the catalytic activity of Ag and $\mathrm{Au}$ clusters physically deposited onto commercial titanium dioxide $\left(\mathrm{TiO}_{2}\right)$ powders with the MACS in the catalytic ozonation of nitrophenol. Compared to traditional catalysts reported in the literature, the catalysts produced by the MACS exhibit at least comparable activities and show excellent reusability without evident degradation after five cycles.

\section{EXPERIMENTAL METHODS}

2.1. Cluster Catalyst Preparation. The $\mathrm{Au}$ and $\mathrm{Ag}$ cluster catalysts used in this work were prepared with a new MACS system at Swansea University (MACS 3 ). Figure 1 shows a photograph and schematic diagram of the system. The new MACS 3 system consists of two vacuum chambers: the cluster deposition chamber and a sample load-lock chamber. In the deposition chamber, the matrix is first prepared on an oxygen-free $\mathrm{Cu}$ support mounted on a cold stage that is cooled to around $20 \mathrm{~K}$ by a closed-loop helium cryocooler (Sumitomo Heavy Industries, RDK-500E). The matrix is then produced by depositing metal atoms (here $\mathrm{Ag}$ or $\mathrm{Au}$ ) onto the support from a thermal effusion cell (Createc, HTC) while simultaneously introducing argon (Ar) gas into the chamber. Once the matrix is generated, a deposition cup (stainless steel, $10 \mathrm{~cm}$ in diameter and $2 \mathrm{~cm}$ in height) containing powder supports $\left(1 \mathrm{~g}, \mathrm{TiO}_{2}\right.$, P25 from Sigma-Aldrich, U.K.) is transferred to a position beneath the matrix support to harvest the clusters. The matrix is then sputtered with an Ar-ion beam $(\sim 2 \mathrm{~mA}$, Gencoa ion source) to generate a sequence of collision cascades in which the metal atoms are condensed together and ripened in a dynamic irradiated environment. Eventually, the ripened clusters are sputtered out of the matrix. During the deposition, the powder supports were mechanically stirred by a metal comb stirrer to maximize the powder particle surface area exposure to the cluster beam.
Compared to the previous MACS system, ${ }^{13}$ the new MACS 3 system shows several improvements: (i) a larger matrix support with a working planar-projected surface area of $>100 \mathrm{~cm}^{2}$, (ii) a higher cooling capacity cryocooler with $80 \mathrm{~W}$ of cooling power at $30 \mathrm{~K}$, (iii) a high-capacity powder system allowing up to $100 \mathrm{~g}$ of powders to be mechanically stirred-the stirring system replaces the previous vibration cup, and (iv) a higher-current ion source, which can deliver a sputtering current of $>100 \mathrm{~mA}$. The cluster yield in the MACS has been shown to be roughly linearly proportional to the sputtering current (about 1 cluster is emitted per $100 \mathrm{Ar}^{+}$ion impacts), 9 so the upgraded system should allow the production of up to $\sim 1 \mathrm{~g}$ of clusters $\left(\mathrm{Au}_{100}\right)$ per hour, assuming all of the clusters produced are collected. However, in this first experiment with MACS 3, a conservative sputtering current of $\sim 2 \mathrm{~mA}$ was used, comparable to the normal level of the previous MACS 2 system.

2.2. Characterization. The morphology imaging of both the $\mathrm{Au}$ and Ag cluster catalysts was performed by a Thermo Fisher Talos scanning/transmission electron microscope (STEM) equipped with a high-angle annual dark-field (HAADF) detector operating with an inner angle of $55 \mathrm{mrad}$ at $200 \mathrm{kV}$. The incident electron beam convergence angle was $21 \mathrm{mrad}$. Cluster size distributions were directly measured from the diameter cross section of individual clusters in the HAADF-STEM images. The STEM samples were prepared by dispersing the catalyst powders decorated with $\mathrm{Au}$ or $\mathrm{Ag}$ clusters in deionized water, sonicating for several minutes and dropcasting onto a copper grid coated with an amorphous carbon film.

The metal loading of the cluster catalysts was characterized by inductively coupled plasma-optical emission spectrometry (ICP-OES) following digestion in a mixed solution of hydrofluoric acid and nitric acid. The Brunauer-Emmett-Teller (BET) surface area and pore radius were measured at $77 \mathrm{~K}$ using $\mathrm{N}_{2}$ adsorption/desorption isotherms (Nova 200e, Quantachrome Instruments). The samples were degassed at $125{ }^{\circ} \mathrm{C}$ for $12 \mathrm{~h}$ before nitrogen adsorption measurements. Quantachrome NovaWin package was used for data acquisition and analysis.

The surface chemistry of the samples was studied by X-ray photoelectron spectroscopy (XPS) after air exposure. The XPS experiments were performed at room temperature and at a base pressure of $1.2 \times 10^{-9}$ mbar using a Kratos AXIS Supra equipped with a monochromatized $\mathrm{Al} \mathrm{K} \alpha \mathrm{X}$-ray source $(1486.6 \mathrm{eV})$ operated at 15 $\mathrm{mA}$. The photoelectron core-level spectra were acquired using a hemispherical analyzer at a pass energy of $160 \mathrm{eV}$ for the wide scan, while the high-resolution spectra were obtained at a passing energy of $40 \mathrm{eV}$. All of the spectra were aligned to the $\mathrm{C}-\mathrm{C}$ carbon peak at $284.8 \mathrm{eV}$. The deconvolution of the spectra was done by CasaXPS software and used to calculate the surface composition.

2.3. Nitrophenol Ozonation Measurements. Ozonation was carried out at room temperature and neutral $\mathrm{pH}$ in a semibatch glass reactor containing $200 \mathrm{~mL}$ of 4-nitrophenol solution $(0.1 \mu \mathrm{M})$ and 50 $\mathrm{mg}$ of catalyst under continuous stirring. $\mathrm{O}_{3}$ was generated from an ozone generator (BMT 803, BMT Messtechnik, Germany) fed by dry air, and the gas concentration was measured by an ozone analyzer 

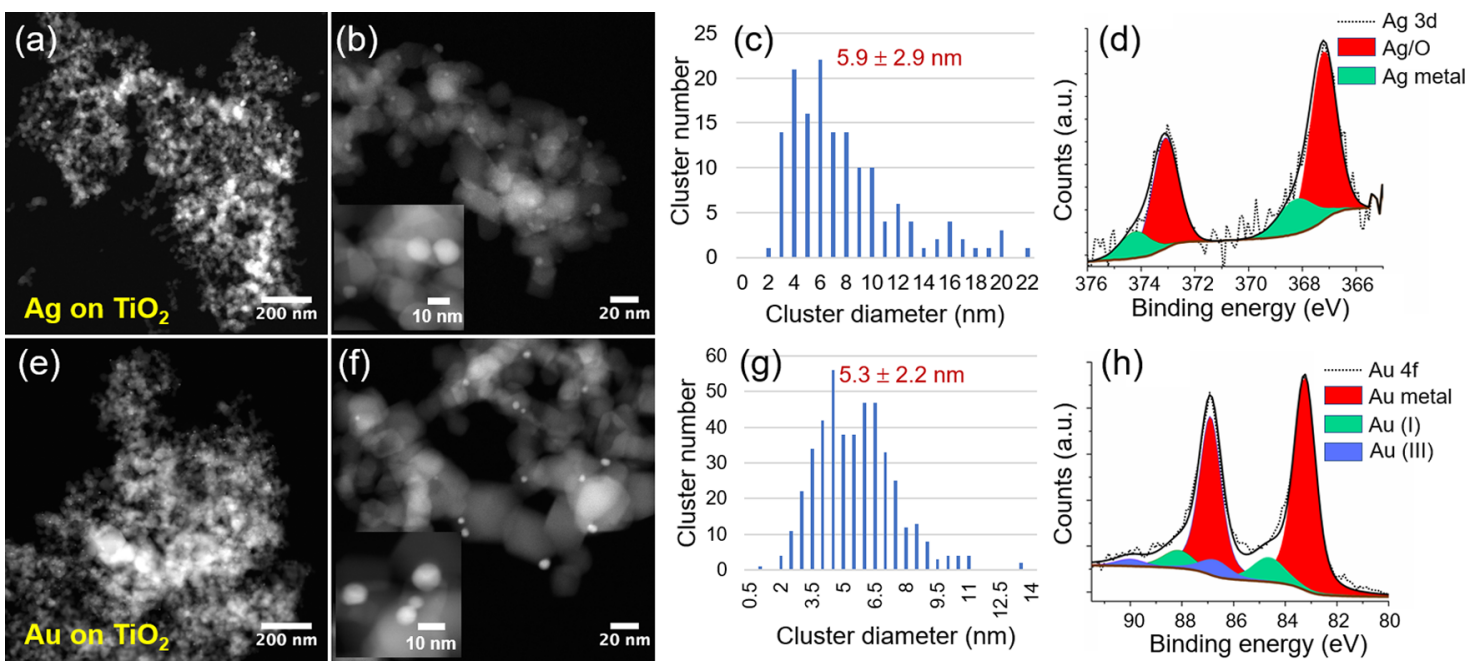

Figure 2. HAADF-STEM images (with three magnifications) and the corresponding cluster diameter distributions and X-ray photoelectron spectroscopy of the cluster catalysts produced. $(\mathrm{a}-\mathrm{d}) \mathrm{Ag}$ on $\mathrm{TiO}_{2}$ and $(\mathrm{e}-\mathrm{h}) \mathrm{Au}$ on $\mathrm{TiO}_{2}$. The $\mathrm{Ag}$ and $\mathrm{Au}$ cluster catalysts show similar peak sizes, which are around 5.9 and $5.3 \mathrm{~nm}$, respectively.
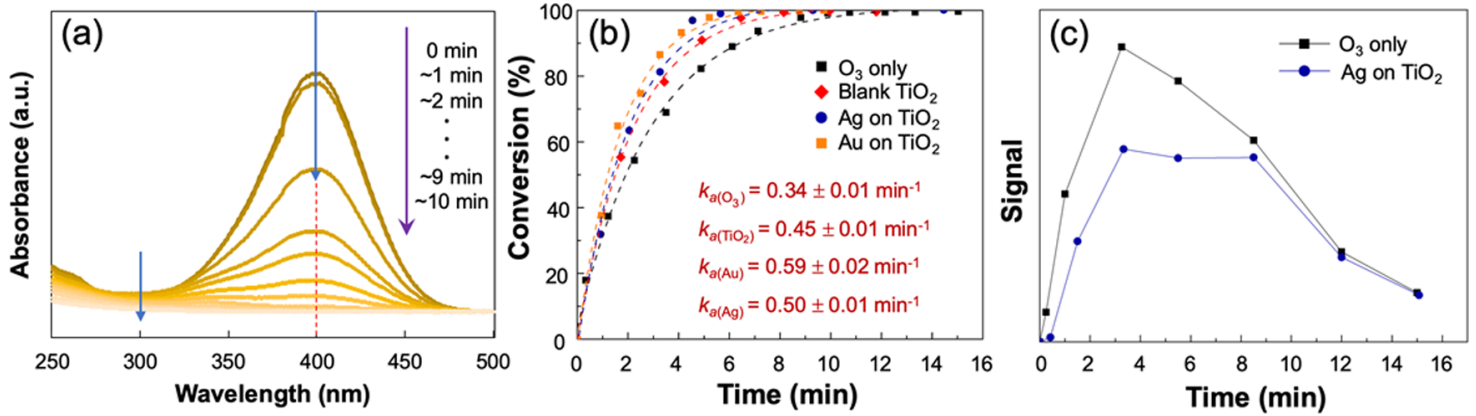

Figure 3. Nitrophenol oxidation by $\mathrm{O}_{3}$ with and without cluster catalysts. (a) UV-vis absorbance spectra during the reaction $(\sim 1$ min intervals), in the presence of $\mathrm{Ag}$ cluster catalyst on $\mathrm{TiO}_{2}$ support. (b) Comparison of nitrophenol conversion as a function of time over the two cluster catalysts as well as blank $\mathrm{TiO}_{2}$ support and without any catalyst. The obtained data were fitted by exponential equations. The inset values are the reaction rate constants. (c) Signal of maleic acid $(\mathrm{m} / z=115)$ in the mass spectra obtained by LC/MS/MS as a function of time for the nitrophenol oxidation by $\mathrm{O}_{3}$ in the presence of $\mathrm{Ag}$ cluster catalyst and without catalyst.

(BMT 963, BMT Messtechnik, Germany). The gaseous feed was bubbled in the reactor at a flow rate of $500 \mathrm{~mL} / \mathrm{min}$. The ozone concentration was adjusted from 3 to $10 \mathrm{~g} / \mathrm{m}^{3}$ NTP (NTP: normal gas temperature and pressure; $0{ }^{\circ} \mathrm{C}$ and $1 \mathrm{~atm}$ ) by varying the power of the ozone generator. The catalytic reaction was initiated by introducing ozone into the reactor using a sintered glass diffuser. The optical absorbance of the reaction solution was recorded by an ultraviolet-visible (UV-vis) spectrophotometer (Lambda 35, PerkinElmer) to monitor the kinetics of the reaction. Sample solutions of approximately $3 \mathrm{~mL}$ were periodically withdrawn from the reactor, followed by air bubbling to quench the ozone reaction and filtration before transferring into a quartz cuvette. The $\mathrm{pH}$ of the sample was adjusted prior to UV-vis spectrum recording. The formation of maleic acid was tracked by liquid chromatographytandem mass spectrometry (LC/MS/MS) $(\mathrm{m} / z$ 115). The LC/MS/ MS analysis was performed on an Agilent 1200 series liquid chromatograph system coupled to a 6410 series triple quadrupole mass spectrometer. The chromatographic conditions were: mobile phase, $50 \% \mathrm{v}$ water: $50 \% \mathrm{v}$ methanol; flow rate, $0.4 \mathrm{~mL} / \mathrm{min}$; injection volume, $10 \mu \mathrm{L}$.

\section{RESULTS AND DISCUSSION}

Two different cluster catalysts were prepared by deposition of $\mathrm{Ag}$ and $\mathrm{Au}$ onto $\mathrm{TiO}_{2}$ powder supports. Figure 2 shows typical HAADF-STEM images (with three magnifications) and the corresponding cluster diameter distributions and X-ray photo- electron spectra of these two samples. In both cases, dense metal clusters are found well dispersed on the supports without severe agglomeration. As the intensity contrast in HAADF images reflects the $Z$ number of the atom (where $Z$ is the elemental atomic number), ${ }^{23,24}$ the observed Au clusters are much brighter than the $\mathrm{Ag}$ clusters. For the cluster diameter distribution, $\mathrm{Ag}$ and $\mathrm{Au}$ cluster catalysts show similar peak sizes, but it is slightly broader in the case of Ag. The peak size for the Ag cluster is around 5.9 and $5.3 \mathrm{~nm}$ for the Au cluster. Compared to the previously reported agitation method, ${ }^{19}$ the improved mixing method (mechanical stirring by a metal comb) exhibits a much better performance without forming large metal aggregates. Most clusters produced by the MACS are neutral, so they are expected to soft-land on the support. The BET results in Table S1 show that after the cluster deposition, the sample surface area and pore size are decreased as expected, compared to the blank $\mathrm{TiO}_{2}$ supports. This further confirms that metal clusters are well dispersed on the supports. ICP-OES and XPS were used to measure the cluster loading for these two samples, which calculated the average metal loading for the $\mathrm{Ag}$ catalyst to be 0.15 and 0.55 wt \%, respectively, for Au catalyst, as seen in Table S1.

Figure 2d,h shows the $\mathrm{Ag} \mathrm{3d}$ and $\mathrm{Au} 4 \mathrm{f}$ high-resolution spectra for the $\mathrm{Ag}$ and $\mathrm{Au}$ clusters on $\mathrm{TiO}_{2}$ supports after air 

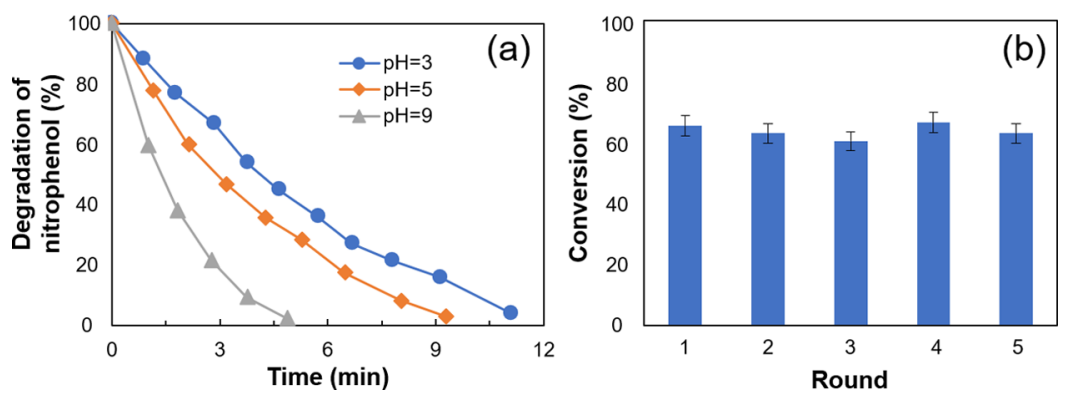

Figure 4. (a) Degradation of nitrophenol as a function of time during ozonation in the presence of $\mathrm{Ag}$ cluster catalyst at different $\mathrm{pH}$ values. (b) Reusability test of Ag cluster catalyst: Nitrophenol conversion after $2 \mathrm{~min}$. Error bars were obtained from repeated experiments.

exposure. The Ag 3d region for the Ag sample consists of two main doublet peaks in Figure 2d. The peak at $368.2 \mathrm{eV}$ (green) corresponds to the metallic silver and is in good agreement with the literature. ${ }^{25}$ The peak with a higher intensity (red) located at $\sim 1 \mathrm{eV}$ lower binding energy coincides with the known peak position for silver oxide $(\mathrm{AgO}){ }^{26}$ Thus, a proportion of the $\mathrm{Ag}$ clusters in the $\mathrm{Ag} / \mathrm{TiO}_{2}$ catalyst is, as expected, oxidized after air exposure. The clusters may be oxidized directly or at the interface with $\mathrm{TiO}_{2}$, as reported previously for $\mathrm{Ru}$ and Pd clusters on oxide supports. ${ }^{27}$ For $\mathrm{Au}$ in Figure $2 \mathrm{~h}$, fitting the $\mathrm{Au} 4 \mathrm{f}$ spectrum using asymmetric line shape shows the clusters are mainly in the metallic state. The $\mathrm{Au} 4 \mathrm{f}$ region shows well-separated spin-orbit components $(\Delta$ $=3.7 \mathrm{eV}$ ). The main peak is located at $83.2 \mathrm{eV}$ compared to 84 $\mathrm{eV}$ often reported in the literature. ${ }^{28}$ This negative shift of 0.8 $\mathrm{eV}$ in the binding energy can be explained by a reduction of the coordination number of $\mathrm{Au}$ atoms ${ }^{29}$ or by electron transfer from the $\mathrm{TiO}_{2}$ to the $\mathrm{Au}$ cluster. The other doublet peaks in the $\mathrm{Au} 4 \mathrm{f}$ spectra at 84.6 and $86.7 \mathrm{eV}$ are commonly observed in $\mathrm{Au}$ clusters and attributed to $\mathrm{Au}^{1+}$ and $\mathrm{Au}^{3+}$ states, respectively.

The synthesized cluster catalysts were investigated in the oxidation of nitrophenol by $\mathrm{O}_{3}$. Catalysts $(50 \mathrm{mg})$ were added to the solution followed by introducing $\mathrm{O}_{3}$ gas to the solution. The optical absorbance was recorded to monitor the progress of the reaction. Figure 3a shows typical UV-vis absorbance spectra for nitrophenol oxidation in the presence of Ag cluster on the $\mathrm{TiO}_{2}$ catalyst. It can be seen that the peak intensity at $400 \mathrm{~nm}$, which corresponds to the nitrophenol concentration, ${ }^{30}$ decreases rapidly over the reaction time, and eventually full conversion is achieved. Since nitrophenol can also be oxidized directly by $\mathrm{O}_{3}$ itself, $^{31}$ the nitrophenol conversion rates over the two cluster catalysts, blank $\mathrm{TiO}_{2}$ support, and in the absence of any catalyst were all obtained and compared in Figure $3 \mathrm{~b}$. While $100 \%$ nitrophenol conversion was achieved in all of the cases, the complete conversion time was $\sim 13 \mathrm{~min}$ without catalysts. It took $9.7 \mathrm{~min}$ for the blank $\mathrm{TiO}_{2}$ powder support and 7.6 (7.3) min for $\mathrm{Ag}(\mathrm{Au})$ cluster catalysts. This confirms that the cluster catalysts accelerate the reaction.

The mechanism of nitrophenol ozonation is complex, involving mass transfer, direct molecular ozone, and indirect (i.e., hydroxyl radical) reactions, which lead to the formation of several intermediates (e.g., dihydroxybenzenes and unsaturated carboxylic acids); they further react with ozone and hydroxyl radicals. As the reaction progresses over time, interference with the main reaction becomes significant. As a result, the kinetics of nitrophenol oxidation are considered only within the first few minutes of reaction. This was supported by following the kinetics of maleic acid formation, $m / z$ 115, using liquid chromatography-tandem mass spectrometry (LC/MS/MS); maleic acid is a product of the main reaction of ozone with nitrophenol. As shown in Figure 3c, the formation of maleic acid peaks at about $4 \mathrm{~min}$, followed by a decline, so competing reactions manifestly take place after about $4 \mathrm{~min}$ from the start of the experiment. A pseudo-first-order reaction with an apparent reaction rate constant, $k_{\text {app}}$, was suitably used to describe the experimental data below $4 \mathrm{~min}$ in Figure $3 \mathrm{~b}$. The values of $k_{\text {app }}$ provide a basis to compare the rates of nitrophenol oxidation by the various systems used in the study. According to the experimental results, $k_{\text {app }}$ is $0.34 \pm 0.01 \mathrm{~min}^{-1}$ for ozone alone, and with the addition of $\mathrm{Au}(\mathrm{Ag})$ clusters, the rate constant increases to $0.59 \pm 0.02 \mathrm{~min}^{-1}(0.50 \pm 0.01$ $\left.\mathrm{min}^{-1}\right)$. This confirms the addition of cluster catalyst accelerates the reaction. Since the loading of $\mathrm{Ag}$ is slightly lower than that for Au cluster catalyst, the normalized reaction rate constant, $k_{\text {nor }}$, shows that the Ag catalyst is more active than Au in Table S2. This behavior can be explained by the enhanced decomposition of ozone to strong oxidative radicals, such as ${ }^{\bullet} \mathrm{OH}$ and $\mathrm{O}_{2}{ }^{\bullet-}$, on the $\mathrm{Au}^{32}$ and $\mathrm{Ag}^{33}$ catalyst surfaces and further promoted by the Lewis acid sites $^{34}$ of $\mathrm{AgO}$, identified in the characterization section.

The rate constants obtained here with the CBD catalysts prepared with the MACS $\left(0.59 \pm 0.02 \mathrm{~min}^{-1}\right.$ for Au and 0.50 $\pm 0.01 \mathrm{~min}^{-1}$ for $\mathrm{Ag}$ ) are higher than those reported with catalysts prepared by traditional chemical methods. For example, a calcined bauxite ore catalyst gave a pseudo-firstorder rate constant of $0.194 \mathrm{~min}^{-1}, 35$ while the mesoporous $\alpha$ $\mathrm{MnO}_{2}$ catalyst gave a rate constant of $0.052 \mathrm{~min}^{-1}$. ${ }^{36}$ This is similar to the value of $0.055 \mathrm{~min}^{-1}$ for a $\mathrm{TiO}_{2}$ catalyst $^{37}$ and $0.0043 \mathrm{~min}^{-1}$ for a titanium dioxide-magnetite composite. ${ }^{38}$ It can hence be concluded that the $\mathrm{Ag}$ and $\mathrm{Au}$ clusters on $\mathrm{TiO}_{2}$ catalysts are promising candidates for the heterogeneous catalytic ozonation reaction with application in water treatment and environmental protection.

The nitrophenol oxidation reaction was also performed at three different values of $\mathrm{pH}$ in Figure $4 \mathrm{a}$. It can be seen that the degradation of nitrophenol is clearly enhanced at alkaline $\mathrm{pH}$. The reaction reaches a conversion level of $>95 \%$ in 5 min when the $\mathrm{pH}$ is $\sim 9$. When the $\mathrm{pH}$ is decreased to 5 , the reaction takes almost double the time, $\sim 9 \mathrm{~min}$, to reach $95 \%$, or $\sim 11$ min at $\mathrm{pH}$ 3. The strongly $\mathrm{pH}$-dependent rate result is consistent with other reports ${ }^{39,40}$ that the decomposition of ozone into reactive radicals is catalyzed by $\mathrm{OH}^{-}$. The reusability of catalyst is one of the main advantages of heterogeneous catalysts compared to homogeneous catalysts. To investigate our catalyst reusability, the deposited Ag cluster catalyst was recovered and reused five times in succession, in Figure $4 \mathrm{~b}$, which shows the 4-nitrophenol conversion level 
after 2 min of reaction for each cycle. The conversion reached $60 \%$ each cycle, which indicates that the cluster catalyst has excellent stability. Error bars shown in the figure $(\sim 5 \%)$ were obtained from repeated experiments. Thus, no deactivation of the catalyst was apparent after reuse. Together, the results suggest that deposition of metal clusters on oxides is a promising new route to enhance the robust catalytic activity of heterogeneous catalysts for water ozonation.

\section{CONCLUSIONS}

In conclusion, the catalytic activities of physically deposited $\mathrm{Ag}$ and $\mathrm{Au}$ clusters on $\mathrm{TiO}_{2}$ were demonstrated in the oxidation of nitrophenol by ozone in aqueous solution. The cluster catalysts were prepared by a new MACS cluster beam deposition system and deposited onto commercial $\mathrm{TiO}_{2}$ powder at the gram scale. Characterization techniques, including STEM, BET, and XPS, revealed that clusters were densely deposited onto the support without severe surface aggregation. The two cluster catalysts show similar size distributions, with peak sizes of around $5.9 \mathrm{~nm}$ for the $\mathrm{Ag}$ catalyst and $5.3 \mathrm{~nm}$ for the $\mathrm{Au}$. Catalytic results demonstrated that both the deposited $\mathrm{Ag}$ and $\mathrm{Au}$ cluster-based catalysts enhanced the catalytic activity compared to pure ozonation of nitrophenol and blank $\mathrm{TiO}_{2}$ powders. With respect to the catalysts produced by traditional chemical methods reported in the literature, the cluster catalysts made with the MACS exhibited at least comparably high activities. This study demonstrates a new route to prepare physically deposited cluster catalysts with high activities for heterogeneous catalysis in solution and specially the catalytic ozonation of a model pollutant for water treatment.

\section{ASSOCIATED CONTENT}

\section{SI Supporting Information}

The Supporting Information is available free of charge at https://pubs.acs.org/doi/10.1021/acsami.0c05955.

Summary of the metal loading and BET results (Table S1); comparison of the intrinsic reaction rate constant normalized by the total number of moles of metal for the nitrophenol reduction catalyzed by $\mathrm{Au}$ and $\mathrm{Ag}$ cluster catalysts (Table S2) (PDF)

\section{AUTHOR INFORMATION}

\section{Corresponding Author}

Richard E. Palmer - College of Engineering, Swansea University, Swansea SA1 8EN, U.K.; ○ orcid.org/0000-0001-87288083; Email: R.E.Palmer@Swansea.ac.uk

\section{Authors}

Rongsheng Cai - College of Engineering, Swansea University, Swansea SA1 8EN, U.K.; 10 orcid.org/0000-0002-2148-0563

Francesca Martelli - Department of Industrial Chemistry "Toso Montanari", Alma Mater Studiorum-University of Bologna, 40136 Bologna, Italy

Jerome Vernieres - College of Engineering, Swansea University, Swansea SA1 8EN, U.K.; 10 orcid.org/0000-0003-4841-8994

Stefania Albonetti - Department of Industrial Chemistry "Toso Montanari", Alma Mater Studiorum-University of Bologna, 40136 Bologna, Italy

Nikolaos Dimitratos - Department of Industrial Chemistry "Toso Montanari", Alma Mater Studiorum-University of Bologna, 40136 Bologna, Italy
Chedly Tizaoui - College of Engineering, Swansea University, Swansea SA1 8EN, U.K.; (1) orcid.org/0000-0003-2159-7881

Complete contact information is available at:

https://pubs.acs.org/10.1021/acsami.0c05955

\section{Notes}

The authors declare no competing financial interest.

\section{ACKNOWLEDGMENTS}

The authors are thankful for financial support from the EPSRC (Grant Reference No. EP/ K006061/2) and the European Union's Horizon 2020 program through the CritCat project under Grant Agreement No. 686053. This research was supported by IMPACT, the Institute of Innovative Materials, Processing and Numerical Technologies. IMPACT was partfunded by the European Regional Development Fund through the Welsh Government and Swansea University. The authors would like to acknowledge the assistance provided by Swansea University College of Engineering AIM Facility, which was funded in part by the EPSRC (EP/M028267/1), the European Regional Development Fund through the Welsh Government (80708), and the Ser Solar project via the Welsh Government. Rongsheng Cai thanks support from the EPSRC (Grant Reference No. EP/P009050/1). The authors thank the Erasmus program for providing the opportunity to Francesca Martelli to spend 3 months in Swansea University. They thank Dr. Tugce Ayvali, University of Oxford, for facilitating the ICP measurements.

\section{REFERENCES}

(1) Palmer, R. E.; Cai, R.; Vernieres, J. Synthesis without Solvents: The Cluster (Nanoparticle) Beam Route to Catalysts and Sensors. Acc. Chem. Res. 2018, 51, 2296-2304.

(2) Cai, R.; Jian, N.; Murphy, S.; Bauer, K.; Palmer, R. E. A New Method to Prepare Colloids of Size-controlled Clusters from a Matrix Assembly Cluster Source. APL Mater. 2017, 5, No. 053405.

(3) Vernieres, J.; Steinhauer, S.; Zhao, J.; Grammatikopoulos, P.; Ferrando, R.; Nordlund, K.; Djurabekova, F.; Sowwan, M. SiteSpecific Wetting of Iron Nanocubes by Gold Atoms in Gas-Phase Synthesis. Adv. Sci. 2019, 6, No. 1900447.

(4) Plant, S. R.; Cao, L.; Palmer, R. E. Atomic Structure Control of Size-selected Gold Nanoclusters during Formation. J. Am. Chem. Soc. 2014, 136, 7559-7562.

(5) Halder, A.; Curtiss, L. A.; Fortunelli, A.; Vajda, S. Perspective: Size Selected Clusters for Catalysis and Electrochemistry. J. Chem. Phys. 2018, 148, No. 110901.

(6) von Issendorff, B.; Palmer, R. E. A New High Transmission Infinite Range Mass Selector for Cluster and Nanoparticle Beams. Rev. Sci. Instrum. 1999, 70, 4497-4501.

(7) Tyo, E. C.; Vajda, S. Catalysis by Clusters with Precise Numbers of Atoms. Nat. Nanotechnol. 2015, 10, 577-588.

(8) Palmer, R. E.; Cao, L.; Yin, F. Note: Proof of Principle of a New Type of Cluster Beam Source with Potential for Scale-up. Rev. Sci. Instrum. 2016, 87, No. 046103.

(9) Ellis, P. R.; Brown, C. M.; Bishop, P. T.; Yin, J.; Cooke, K.; Terry, W. D.; Liu, J.; Yin, F.; Palmer, R. E. The Cluster Beam Route to Model Catalysts and Beyond. Faraday Discuss. 2016, 188, 39-56.

(10) Oiko, V. T. A.; Mathieu, T.; Cao, L.; Liu, J.; Palmer, R. E. Note: Production of Silver Nanoclusters Using a Matrix-Assembly Cluster Source with a Solid $\mathrm{CO}_{2}$ Matrix. J. Chem. Phys. 2016, 145, No. 166101.

(11) Zhao, J.; Cao, L.; Palmer, R. E.; Nordlund, K.; Djurabekova, F. Formation and Emission Mechanisms of $\mathrm{Ag}$ Nanoclusters in the Ar Matrix Assembly Cluster Source. Phys. Rev. Mater. 2017, 1, No. 066002. 
(12) Spadaro, M. C.; Zhao, J.; Terry, W. D.; Liu, J.; Yin, F.; Djurabekova, F.; Palmer, R. E. Angular Dependence of Nanoparticle Generation in the Matrix Assembly Cluster Source. Nano Res. 2019, 12, 3069-3074.

(13) Cai, R.; Cao, L.; Griffin, R.; Chansai, S.; Hardacre, C.; Palmer, R. E. Scale-up of Cluster Beam Deposition to the Gram Scale with the Matrix Assembly Cluster Source for Heterogeneous Catalysis (Propylene Combustion). AIP Adv. 2020, 10, No. 025314.

(14) Bright, D. A.; Healey, N. Contaminant Risks From Biosolids Land Application: Contemporary Organic Contaminant Levels in Digested Sewage Sludge from Five Treatment Plants in Greater Vancouver, British Columbia. Environ. Pollut. 2003, 126, 39-49.

(15) Xiong, Z.; Zhang, H.; Zhang, W.; Lai, B.; Yao, G. Removal of Nitrophenols and their Derivatives by Chemical Redox: A Review. Chem. Eng. J. 2019, 359, 13-31.

(16) Bae, S.; Gim, S.; Kim, H.; Hanna, K. Effect of $\mathrm{NaBH}_{4}$ on Properties of Nanoscale Zero-Valent Iron and Its Catalytic Activity for Reduction of p-nitrophenol. Appl. Catal., B 2016, 182, 541-549.

(17) Mei, Q.; Cao, H.; Han, D.; Li, M.; Yao, S.; Xie, J.; Zhan, J.; Zhang, Q.; Wang, W.; He, M. Theoretical Insight into the Degradation of p-nitrophenol by $\mathrm{OH}$ Radicals Synergized with Other Active Oxidants in Aqueous Solution. J. Hazard. Mater. 2020, 389, No. 121901.

(18) Hu, L.; Wang, P.; Liu, G.; Zheng, Q.; Zhang, G. Catalytic Degradation of p-nitrophenol by Magnetically Recoverable $\mathrm{Fe}_{3} \mathrm{O}_{4}$ as a Persulfate Activator under Microwave Irradiation. Chemosphere 2020, 240, No. 124977.

(19) Cai, R.; Ellis, P. R.; Yin, J.; Liu, J.; Brown, C. M.; Griffin, R.; Chang, G.; Yang, D.; Ren, J.; Cooke, K.; Bishop, P. T.; Theis, W.; Palmer, R. E. Performance of Preformed $\mathrm{Au} / \mathrm{Cu}$ Nanoclusters Deposited on $\mathrm{MgO}$ Powders in the Catalytic Reduction of 4Nitrophenol in Solution. Small 2018, 14, No. 1703734.

(20) Nawaz, F.; Cao, H.; Xie, Y.; Xiao, J.; Chen, Y.; Ghazi, Z. A. Selection of Active Phase of $\mathrm{MnO}_{2}$ for Catalytic Ozonation of 4nitrophenol. Chemosphere 2017, 168, 1457-1466.

(21) Jung, H.; Choi, H. Catalytic Decomposition of Ozone and Para-Chlorobenzoic Acid (pCBA) in the Presence of Nanosized $\mathrm{ZnO}$. Appl. Catal., B 2006, 66, 288-294.

(22) Yang, Y.; Ma, J.; Qin, Q.; Zhai, X. Degradation of Nitrobenzene by $\mathrm{Nano}^{-\mathrm{TiO}_{2}}$ Catalyzed Ozonation. J. Mol. Catal. A: Chem. 2007, 267, 41-48.

(23) Wang, Z. W.; Palmer, R. E. Intensity Calibration and Atomic Imaging of Size-selected $\mathrm{Au}$ and Pd Clusters in Aberration-corrected HAADF-STEM. J. Phys.: Conf. Ser. 2012, 371, No. 012010.

(24) Mejía-Rosales, S. J.; Fernandez-Navarro, C.; Perez-Tijerina, E.; Blom, D. A.; Allard, L. F.; Jose-Yacaman, M. On the Structure of Au/ Pd Bimetallic Nanoparticles. J. Phys. Chem. C 2007, 111, 1256-1260.

(25) Seah, M. P.; Gilmore, I. S.; Beamson, G. XPS: Binding Energy Calibration of Electron Spectrometers 5-Re-evaluation of the Reference Energies. Surf. Interface Anal. 1998, 26, 642-649.

(26) Kaushik, V. K. XPS Core Level Spectra and Auger Parameters for Some Silver Compounds. J. Electron Spectrosc. Relat. Phenom. 1991, 56, 273-277.

(27) Porkovich, A.; Ziadi, Z.; Kumar, P.; Kioseoglou, J.; Jian, N.; Weng, L.; Steinhauer, S.; Vernieres, J.; Grammatikopoulos, P.; Sowwan, M. In Situ Observation of Metal to Metal Oxide Progression: A Study of Charge Transfer Phenomenon at $\mathrm{Ru}-\mathrm{CuO}$ Interfaces. ACS Nano 2019, 13, 12425-12437.

(28) Lim, D. C.; Lopez-Salido, I.; Dietsche, R.; Bubek, M.; Kim, Y. D. Size-Selectivity in the Oxidation Behaviors of Au Nanoparticles. Angew. Chem., Int. Ed. 2006, 45, 2413-2415.

(29) Radnik, J.; Mohr, C.; Claus, P. On the Origin of Binding Energy Shifts of Core Levels of Supported Gold Nanoparticles and Dependence of Pretreatment and Material Synthesis. Phys. Chem. Chem. Phys. 2003, 5, 172-177.

(30) Saha, S.; Pal, A.; Kundu, S.; Basu, S.; Pal, T. Photochemical Green Synthesis of Calcium-Alginate-Stabilized $\mathrm{Ag}$ and $\mathrm{Au}$ Nanoparticles and their Catalytic Application to 4-nitrophenol Reduction. Langmuir 2010, 26, 2885-2893.
(31) Beltrán, F. J.; Gómez-Serrano, V.; Durán, A. Degradation Kinetics of p-nitrophenol Ozonation in Water. Water Res. 1992, 26, 9-17.

(32) Pugazhenthiran, N.; Sathishkumar, P.; Murugesan, S.; Anandan, $S$. Effective Degradation of Acid Orange 10 by Catalytic Ozonation in the Presence of $\mathrm{Au}-\mathrm{Bi}_{2} \mathrm{O}_{3}$ Nanoparticles. Chem. Eng. J. 2011, 168, $1227-1233$

(33) Morozov, P. A.; Abkhalimov, E. V.; Chalykh, A. E.; Pisarev, S. A.; Ershov, B. G. Interaction of Silver Nanoparticles with Ozone in Aqueous Solution. Colloid J. 2011, 73, 248-252.

(34) Yan, L.; Bing, J.; Wu, H. The Behavior of Ozone on Different Iron Oxides Surface Sites in Water. Sci. Rep. 2019, 9, No. 14752.

(35) Chen, C.; Chen, H.; Yu, J.; Han, C.; Yan, G.; Guo, S. pNitrophenol Removal by Bauxite Ore Assisted Ozonation and its Catalytic Potential. Clean: Soil, Air, Water 2015, 43, 1010-1017.

(36) Nawaz, F.; Xie, Y.; Cao, H.; Xiao, J.; YueqiuWang; Zhang, X.; Li, M.; Duan, F. Catalytic Ozonation of 4-nitrophenol over a Mesoporous $\alpha-\mathrm{MnO}_{2}$ with Resistance to Leaching. Catal. Today 2015, 258, 595-601.

(37) Shokri, A. Degradation of 4-Nitrophenol from Industrial Wastewater by Nano Catalytic Ozonation. Int. J. Nano Dimens. 2016, $7,160-167$.

(38) Kazakov, D. A.; Vol'khin, V. V.; Kaczmarski, K.; Gulenova, Y. O.; Obirina, M. N.; Rozhina, D. A. Catalytic Ozonation of 4Nitrophenol in the Presence of Magnetically Separable Titanium Dioxide - Magnetite Composite. Eurasian Chem.-Technol. J. 2015, 17, 309-316.

(39) Shanthi, S.; Yenkie, M.K.N. P-Nitrophenol: A Model Compound for the Study of Role of $\mathrm{PH}$ in the Reaction of Ozone with Phenols. J. Pollut. Eff. Control 2016, 4, No. 1000168.

(40) Jin, X.; Peldszus, S.; Huck, P. M. Reaction Kinetics of Selected Micropollutants in Ozonation and Advanced Oxidation Processes. Water Res. 2012, 46, 6519-6530. 